\title{
Early Assessment of Health Technologies
}

\author{
Oleg N. Shishatskiy* \\ Institute of Economics and Industrial Engineering SB RAS \\ 17 Academician Lavrentyev, Novosibirsk, 630090, Russia
}

Received 27.02.2019, received in revised form 22.05.2019, accepted 05.06.2019

\begin{abstract}
This article provides an analysis of current views on the assessment of health technologies at early stages of their development to create medical products and services that have additional value. Methods that can be used to assess the commercial effectiveness of medical products and services at early stages of their development and to compare them with potential competitors are described. The review may be useful to those who are involved in the development of new medical technologies and seek to increase the investment attractiveness of their proposals.
\end{abstract}

Keywords: quality of life, QALY, early assessment of health technologies, investment attractiveness, medical technology development.

Citation: Shishatskiy O.N. Early assessment of health technologies. J. Sib. Fed. Univ. Biol., 2019, 12(3), 253-257. DOI: $10.17516 / 1997-1389-0299$.

\section{Ранняя оценка медицинских технологий}

О.Н. Шишацкий

Институт экономики и организации промышленного производства СО РАН

Россия, 630090, Новосибирск, пр. Академика Лаврентьева, 17

Проанализированы современные представления о проведении ранней оценки создаваемых медищинских технологий с ичелью разработки медицинских продуктов и услуг, обладающих дополнительной ценностью. Описаны способы определения коммерческой эффективности медиџинских продуктов и услуг на ранних этапах их разработки и использования для сравнения с потенциальными конкурентами. Обзор может быть полезен лицам, вовлеченным в разработку

(C) Siberian Federal University. All rights reserved

This work is licensed under a Creative Commons Attribution-NonCommercial 4.0 International License (CC BY-NC 4.0).

* Corresponding author E-mail address: shishatskiy@mail.ru 
новых медицинских технологий и заинтересованным в повыщении их инвестицчионной привлекательности.

Ключевые слова: качество жизни, QALY, ранняя оценка медицинских технологий, инвестиционная привлекательность, разработка медицинских технологий.

In developed countries, health systems function according to the principles of valuebased health care, which means measuring the cost of medical products and services against the effectiveness of their impact on the quality of life of patients.

The world's largest economies allocate significant resources to improving the efficiency of their health systems, including the development of new medical products and services. An outstanding trend in this area is the analysis of prospected products and services at early stages of their development, which may help improve their efficiency and reduce investment risks. This paper presents an analytical review of scientific research in this area and focuses on the rationales for creating medical technologies that have the potential for additional value.

In this paper, health technologies (HTs) are understood as methods of diagnostics, treatment and prevention of diseases and the rehabilitation of patients using vaccines, drugs, and medical devices, and surgical procedures and technologies designed to protect and preserve human health. Health technology assessment (HTA) is a common practice worldwide. This area of research has emerged because it could provide relevant information for choosing optimal ways to offer medical care within a limited health budget.

A definition and the general provisions of HTA can be found in the National Standards for the Evaluation of Medical Technologies approved by the Federal Agency for Technical Regulation and Metrology of the Russian Federation in 2014. "Evaluation of a health technology is a comprehensive process of summarising information about a health technology, which aims at optimising decision-making and examines short- and long-term medical, social, economic and ethical aspects of the development, dissemination and application of a health technology; it is conducted using open, unbiased, systematic and sustainable procedures" (Federal Agency for Technical Regulation..., 2015). It should be noted that all HTs are subject to mandatory evaluation prior to registration even before they enter the market. The key difference is that a pre-registration evaluation is designed to assess the clinical efficacy and safety of an HT compared with a placebo or other drugs, which may not always reflect the interests of society, while the purpose of HTA is to estimate the added value of a new HT compared to the existing common clinical practice.

Earlier, a common criterion to determine the value or effect of an HT was the number of years of life saved. However, most of the presentday health technologies do not always have a significant impact on life expectancy but can dramatically improve life quality, so a notion of the quality-adjusted life year (QALY) has been introduced. This indicator appeared in the UK and is now used in HTA in many countries around the world. In HTA, a variety of different clinical and economic indicators are used; among them is the incremental cost-effectiveness ratio (ICER), a statistical indicator used in clinical and economic analysis (CEA) to determine the relative costeffectiveness of medical interventions. The ICER is calculated as the ratio of the difference in 
costs between two possible interventions to the difference in their effects; it shows the average additional costs that are necessary to obtain an additional unit of effect (value) during the intervention (application of an HT).

The costs of an HT (the ICER value) that the society considers acceptable to pay for obtaining an additional unit of effect (value) from this HT application is called the willingness-topay (WTP) threshold. In other words, the WTP threshold determines the maximum allowable (threshold) ratio of additional health care costs to the unit of added medical effect (value). In recent years, the application of HTA has increased at the early stages of the development of medical products, and this practice is called early health technology assessment (early HTA).

The generally accepted definition of early HTA as "all methods used to inform industry and other stakeholders about the potential value of new medical products in development, including methods to quantify and manage uncertainty", is given by IJzerman et al. (2017). The paper by Omelyanovsky (2014) contains a definition expressing the essence of this concept: "It is an analysis of the investment attractiveness of new technologies carried out at early stages of their development that is called early HTA." Many studies worldwide are focused on the definition of the WTP threshold and calculation of QALYs. Thus, Yagudina et al. (2015) calculated this indicator for the Russian Federation following the methodology of the World Health Organisation with the official US dollar exchange rate set by the Central Bank and the purchasing power parity (PPP) of the rouble to the US dollar, as assessed by the World Bank. The authors concluded that the WTP threshold determined using the PPP is a more objective decision-making tool. In the study by Bezdenezhnykh et al. (2018), the WTP threshold is considered to be a tool for generating restrictive lists of HTs. Therefore, the definition and application of the WTP threshold in HTA will make it possible to optimise the use of authorised (registered) HTs.

Since early HTA is designed to determine the potential value of medical products, the implementation of the recommendations from the above authors will undoubtedly help increase the efficiency of new HTs development. It will be of particular interest to analyse the ICER values for one saved QALY and/or one saved year of life for the HTs that have already received both positive and negative feedback on inclusion in restrictive lists in Russia (Bezdenezhnykh et al., 2018). This indicator may be crucial for the investment attractiveness analysis of new HTs.

We realise that analyses and calculations for all large restrictive lists, for example, the list of vital and essential drugs, will be very costly and time consuming. Furthermore, the obtained result will be practically useless in HT development. When developing a new HT, the ICER calculation for one saved QALY should be done for the comparable drugs, those which the new HT will potentially compete with on the market. Thus, it is proposed to determine the WTP threshold for HTs with which the new medical product will compete. This will allow us to calculate the potential commercial effectiveness of a developed HT after its introduction to the market and more accurately assess the investment attractiveness of its development.

In Russia, there is no experience with applying the QALY and the methodology for calculating this indicator, which complicates the implementation of CEA. The world practice is to use quality of life questionnaires validated for QALYs (they contain a set of utility values that correspond to health conditions), which allows researchers to determine the indicator of effectiveness when conducting HTA. However, no quality of life questionnaire has been validated for use in Russia. This makes 
it difficult to use questionnaires in the Russian Federation to assess the quality of life and to carry out CEA. The paper by Makarova (2018) describes alternative approaches to obtaining utility values for universal questionnaires using forecasting (mapping) based on other indicators of the patient's health status.

Using the QALY as an efficiency criterion is generally accepted when determining the costeffectiveness ratio of additional costs (ICER) and comparing them with the WTP threshold during HTA; however, the QALY often does not take into account a number of other socially important factors that are relevant to a patient and the society as a whole. For example, these factors may include relevance to the patient's social group (children, working-age population, disabled people, etc.) and other characteristics of an HT (country of origin, degree of innovation, compliance with GMP criteria, etc.). A significant portion of new HTs that have high clinical efficacy and lead to a significant improvement in medical outcomes cost more than the WTP threshold. For this reason, patients will have limited access to desirable and effective HTs. Therefore, to evaluate the effect (value) in addition to a CEA, other criteria for evaluating HTs should be considered.

For this reason, the methodology of multi-criteria decision analysis (MCDA) has been introduced. It aggregates heterogeneous, seemingly unrelated criteria into a single indicator of HT value, which takes into account not only the CEA results but also various factors and their relative significance (weights or weight coefficients) and ensures that decisions are transparent and based on reproducible results obtained using this integral numeral indicator. In our opinion, application of the MCDA methodology for assessment at the early stages of development of particular HTs may be useful to determine their efficiency and relevance, especially in cases when the cost of a new HT exceeds the WTP threshold calculated on the basis of QALYs. MCDA is another method used to support decisions at early stages of medical product development. In particular, MCDA has been proposed to support portfolio decisions over a range of technologies where resources are allocated based on future value and development risk (Thokala et al., 2016). One of the main current trends in early HTA is the use of the ICER indicator based on QALYs and its comparison with the WTP threshold. In the Russian Federation, it is proposed to assess HTs using this indicator and compare it with the WTP threshold for a narrow group of comparable drugs, i.e., the products with which the potential HT will compete.

\section{Acknowledgement}

The research was carried out with the plan of research work of IEIE SB RAS, project XI.174. 1.1.(0325-2019-0008) «Economy of Siberia and its regions with external and internal challenges and threats: methods, trends, forecasts», № AAAA-A17-117022250133-9.

\section{References}

Bezdenezhnykh T.P., Musina N.Z., Fedyaeva V.K., Tepcova T.S., Lemeshko V.A., Omelyanovsky V.V. (2018) International experience in determining the cost-effectiveness thresholds. Farmakoekonomika. Modern Pharmacoeconomic and Pharmacoepidemiology, 11(4): 73-80 (in Russian)

Federal Agency for Technical Regulation and Metrology of the Russian Federation, National Standard of the Russian Federation (GOST R 56044-2014) "Evaluation of Medical Technologies", date of introduction 2015.06 .01 (in Russian) 
Ijzerman M.J., Koffijberg H., Fenwick E., Krahn M. (2017) Emerging use of early health technology assessment in medical product development: a scoping review of the literature. Pharmacoeconomics, 35(7): 727-740

Makarova E.I. (2018) Methodology of calculation of QALY in pharmacoeconomic modelling: using questionnaires of study of patient's quality of life. Pharmacoeconomics: Theory and Practice, 6(1): 7-12 (in Russian)

Omelyanovsky V.V. (2014) Early health technology assessment as a tool for evaluating and steering the creation of new medical products. Medical Technologies. Assessment and Choice, 2: 2329 (in Russian)

Thokala P., Devlin N., Marsh K., Baltussen R., Boysen M., Kalo Z., Longrenn T., Mussen F., Peacock S., Watkins J., Ijzerman M. (2016) Multiple criteria decision analysis for health care decision making-an introduction: report 1 of the ISPOR MCDA emerging good practices task force. Value in Health, 19(1): 1-13

Yagudina R.I., Kulikov A.Yu., Ugrekhelidze D.T. (2015) Assessing willingness-to-pay threshold for health technologies in the Russian Federation on the basis of purchasing power parity. Pharmacoeconomics: Theory and Practice, 3(3): 10-14 